\title{
Emotional Cognition without Awareness after Unilateral Temporal Lobectomy in Humans
}

\author{
Yasutaka Kubota, ${ }^{1}$ Wataru Sato, ${ }^{2}$ Toshiya Murai, ${ }^{3}$ Motomi Toichi, ${ }^{4}$ Akio Ikeda, ${ }^{5}$ and Akira Sengoku ${ }^{1}$ \\ ${ }^{1}$ Department of Neuropsychiatry, Faculty of Medicine, Kyoto University, Kyoto, Japan, ${ }^{2}$ Department of Cognitive \\ Psychology in Education, Kyoto University, Kyoto, Japan, ${ }^{3}$ Max-Planck-Institute of Cognitive Neuroscience, Leipzig, \\ Germany, ${ }^{4}$ Health and Medical Services Center, Shiga University, Shiga, Japan, and ${ }^{5}$ Department of Brain \\ Pathophysiology, Faculty of Medicine, Kyoto University, Kyoto, Japan
}

\begin{abstract}
To investigate the function of the amygdala in human emotional cognition, we investigated the electrodermal activity (EDA) in response to masked (unseen) visual stimuli. Six epileptic subjects were investigated after unilateral temporal lobectomy. Emotionally valenced photographic slides (10 negative, 10 neutral) from the International Affective Picture System were presented to their unilateral visual fields under either subliminal or supraliminal conditions. An interaction between hemispheres and emotional valences was found only under the subliminal conditions; greater EDA responses to negative stimuli com-
\end{abstract}

Animal studies have revealed the crucial role of the amygdala in processing emotionally significant stimuli (Weiskrantz, 1956; Geschwind, 1965; Nishijo et al., 1988; Gaffan et al., 1989; Brothers et al., 1990; LeDoux et al., 1990; Nakamura et al., 1992; Goldstein et al., 1996). Lesion and functional imaging studies in human have shown the critical role of the amygdala in recognizing emotional facial expressions, notably negative ones (Adolph et al., 1994, 1995, 1999; Young et al., 1995; Calder et al., 1996; Morris et al., 1996; Breiter et al., 1996; Broks et al., 1998; Hamann and Adolph, 1999).

Recently, functional imaging studies of normal subjects have demonstrated the involvement of the amygdala in subliminal processing of visual stimuli, i.e., processing below the level of awareness (Morris et al., 1998; Whalen et al., 1998). Activation of the amygdala was observed during the presentation of stimuli with high emotional significance such as an angry face, even in the absence of explicit knowledge in the subjects that such stimuli were presented. The results suggest that emotional valence is processed at the subconscious level and that the amygdala plays a crucial role in this process.

Electrodermal activity (EDA) is a measure of autonomic nervous system (ANS) activity frequently used to index complex CNS processes such as emotion (Boucsein, 1992). More specifically, EDA is often used as a monitor of subconscious neural processing of psychologically significant stimuli, as in studies demonstrating that prosopagnosics display normal EDA responses to familiar faces which they cannot identify (Bauer, 1984; Tranel and Damasio, 1988). Recent cerebral stimulation and neuroimaging studies have shown an association between amygdala activation and EDA (Mangina et al., 1996; Furmark et al., 1997). It has also been reported that amygdala lesions in humans caused an impairment in EDA, especially during aversive conditioning and reward-related feedback (Bechara et al., 1995, 1999;

Received March 30, 2000; revised June 20, 2000; accepted June 26, 2000

Correspondence should be addressed to Dr. Yasutaka Kubota, Department of Neuropsychiatry, Faculty of Medicine, Kyoto University, Shogoin-Kawaharacho, Kyoto 606-8507, Japan. E-mail: yka@pluto.dti.ne.jp.

Copyright (C) 2000 Society for Neuroscience $0270-6474 / 00 / 200001-05 \$ 15.00 / 0$ pared with neutral ones were observed when stimuli were presented to the intact hemispheres. The findings suggest that nonconscious emotional processing is reflected in EDA in a different manner from conscious emotional processing. Medial temporal structures, including the amygdala, thus appear to play a critical role in the neural substrates for this automatic processing.

Key words: amygdala; unilateral temporal lobectomy; emotion; emotional visual stimuli; backward masking; awareness; $E D A$

LaBar et al., 1995). Thus, EDA could be regarded as an appropriate method for investigating amygdala function in emotional processing below the level of awareness.

In the present study, using patients after unilateral temporal lobectomy as subjects, EDA was measured during visual presentation of emotionally valenced stimuli both under either conditions of subliminal or supraliminal presentation. Backward masking was applied to realize the subconscious presentation of visual stimuli (Esteves and Öhman, 1993). Visual stimuli were presented to each unilateral visual field (i.e., input to the hemisphere contralateral to the visual field of stimuli presentation), and EDA responses were compared within a subject regarding the stimulated side of the hemisphere (intact side vs lesion side) and emotional valence of the presented stimuli. The present study is, to our knowledge, the first lesion study conducted in human subjects using a subliminal emotional cognition paradigm.

\section{MATERIALS AND METHODS}

\section{Subjects}

Initially, nine subjects who had previously undergone unilateral temporal lobectomies for pharmacologically intractable seizures were investigated. One of these initial subjects was excluded because of a visual fields deficit (see Materials and Methods), and two were excluded because of poor control of seizure and unstable mental state during measurement. Consequently, six patients were selected for data analysis (two males and four females, ages 22-53). They were all right-handed. These patients had

This article is published in The Journal of Neuroscience, Rapid Communications Section, which publishes brief, peer-reviewed papers online, not in print. Rapid Communications are posted online approximately one month earlier than they would appear if printed. They are listed in the Table of Contents of the next open issue of JNeurosci. Cite this article as: JNeurosci, 2000, 20:RC97 (1-5). The publication date is the date of posting online at www.jneurosci.org.

http://www.jneurosci.org/cgi/content/full/4524 


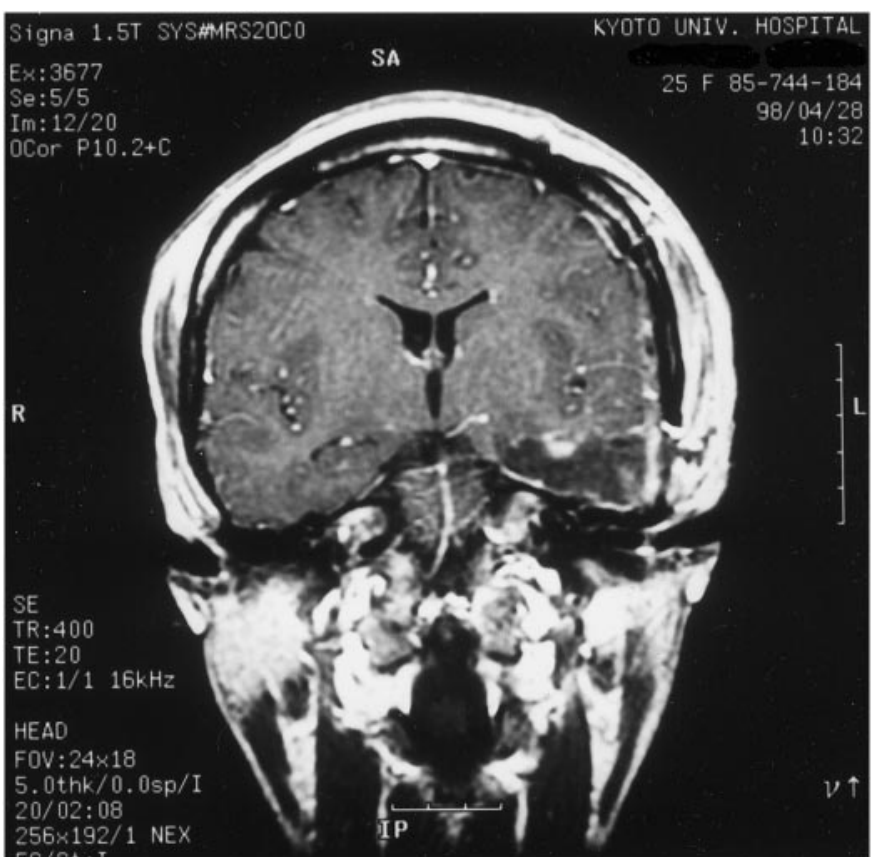

Figure 1. An example of T1-weighted MRI scan in one of the patients after unilateral temporal lobectomy.

undergone standard anterior temporal lobectomy; four patients underwent left temporal lobectomy, and two underwent right temporal lobectomy. The extent of the temporal resection was $4-5 \mathrm{~cm}$ posterior to the temporal pole. The superior temporal gyrus was preserved except for in one patient who underwent additional partial superior temporal gyrectomy. Postsurgical magnetic resonance imagings (MRIs) were obtained in all patients to reexamine the extent of the resection, which confirmed that substantial portions of amygdala was removed in them. Damages to hippocampal formation and surrounding cortices were also found. An example of MRI in one of the patients is shown (Fig. 1). All of these six patients were being maintained on one or more antiepileptic medications and were seizure-free after surgery. The mean score of the Weschler Adult Intelligence Scale-Revised after surgery was 74.4 (61-88). All of the subjects gave written informed consent to participate in this study after the procedure was fully explained.

\section{Stimulus materials}

A set of negative (10 items) and neutral (10 items) slides were selected from the International Affective Picture System (IAPS) (Lang et al., 1995). Negative slides included themes such as frightening animals, human violence, mutilated bodies, etc. Neutral slides consisted of inanimate objects, people with neutral facial expressions, natural landscapes, etc. All subjects were naive to these picture stimuli. A mask of mosaic patterns made of the fragments of these slides was applied in a backward masking procedure.

\section{Apparatus and response measurement}

Picture stimuli were presented on a flat type CRT monitor (Sony GDMF400). The presentation of stimuli was controlled using an NEC personal computer with SuperLab (Cedrus) software. The time lag of presentation in this system was estimated to be within $8 \mathrm{msec}$. The monitor was located $\sim 57.3 \mathrm{~cm}$ in front of the subject, and the size of visual stimuli on the monitor corresponded to 5.0 (horizontal) $\times 8.0^{\circ}$ (vertical) of visual angle. To examine emotional processing in the lesion side and the intact side hemisphere separately, EDA responses were compared within a subject with regard to the visual field to which the stimuli were presented. We used a within-subject approach to avoid a problem associated with large between-subject variability of EDA, which is the major limitation of this measurement technique (Yokota et al., 1991; Claus and Schondorf, 1999). Sympathetic skin response (SSR) was used as the measure of EDA (Claus and Schondorf, 1999). SSR was recorded bilaterally with $\mathrm{Ag}$ / $\mathrm{AgCl}$ electrodes attached to the hypothenar eminences of both hands. Eye movements were also monitored using EOG to confirm that stimuli had been presented only to unilateral visual fields. Physiological signals were digitized at $200 \mathrm{~Hz}$ and recorded for off-line analyses using an NEC digital encephalograph (SYNAFIT 5000). The lower frequency limit was $0.15 \mathrm{~Hz}$, and the upper limit was $15 \mathrm{~Hz}$.

\section{Procedure}

The subjects, with arm electrodes attached, were seated in an armchair in a dark, quiet room at normal ambient temperatures and instructed to look at the monitor situated in front of them.

\section{Assessment session}

Visual field deficit. An assessment of possible visual field deficit because of temporal lobectomy was conducted using the same monitor. Subjects were instructed to look at a fixation point in the center of the monitor, and a target stimulus $\left(2 \times 2^{\circ}\right.$ of visual angle) was presented for $200 \mathrm{msec}$ in one of the corners. Then subjects were asked to point to the place where the target appeared.

Baseline of SSR. SSR was recorded for $5 \mathrm{~min}$ in the resting condition. This measure was regarded as the baseline activity for each subject.

The upper limit of SOA for subliminal presentation. Esteves and Öhman (1993) demonstrated that whether the stimulus onset asynchrony (SOA; i.e., the interval between the onset of the target and the mask) was sufficiently brief, the subjects were not aware of the target stimuli. To assess the upper limit of SOA for subliminal presentation in each subject, five stimuli were presented, and the subject was instructed to describe what they had seen (these stimuli were not used in the following trial session). The stimuli were presented at random to each unilateral visual field using backward masking. The duration of slide presentation was fixed at $30 \mathrm{msec}$ in all subjects and that of mask presentation was 100 msec. Starting from $60 \mathrm{msec}$, SOA was prolonged by $10 \mathrm{msec}$ increments. For each length of SOA, five stimuli were presented. If the subject was aware of at least one of the five stimuli, the corresponding SOA was regarded as the lower limit of conscious recognition for that subject, and an interval $10 \mathrm{msec}$ shorter than that limit was used in the trial session.

\section{Trial session}

Forty successive trials of slide presentation were performed (10 negative, 10 neutral $\times$ left, right visual fields) under subliminal conditions. After a short break, another 40 trials under supraliminal conditions were performed. The order of slide presentation was varied systematically across the subjects. For subliminal conditions, the duration of presentation was fixed at $30 \mathrm{msec}$ in all subjects. SOA was adjusted for each subject, and the mask was presented after that interval. For supraliminal conditions, the presentation period was fixed at $200 \mathrm{msec}$ in all subjects and there was no masking. The interval between each slide presentation was $30 \mathrm{sec}$, and during that period the monitor was blacked out. The subjects were instructed to relax between each of these periods.

A trial consisted of the following phases: (1) A white screen appeared on the monitor and the target (black, cross mark) was presented at the center. (2) The cue sound was delivered $1 \mathrm{sec}$ before the slide presentation. The subject was instructed to look at the target after hearing the cue sound. (3) A photographic slide was presented either to the left or the right side of the target ( $3^{\circ}$ of visual angle from the centerline). (4) SSR was recorded for $10 \mathrm{sec}$ after the presentation of a slide. (5) After the recordings, two questions ("Negative/Neutral?", "What?") were presented on the monitor and subjects were asked to describe how they felt and what they saw during slide presentation phase. This verbal assessment provided a measure of subjective emotional judgement and declarative knowledge of the slide contents.

\section{Data analysis}

The first five trials were not included in the data analysis to minimize the effect of nonrelaxation. Any SSR deflection with a peak latency $<1 \mathrm{sec}$ or $>8 \mathrm{sec}$ was rejected as an artifact. Magnitudes of SSR were used as the measures for subsequent analyses. SSR responses from both left and right hands were scored, and the scorer was blind to the types of affective stimuli and to which hemisphere the stimuli were inputted.

Under subliminal conditions, $2.08 \%$ of the stimuli were correctly identified. These data were excluded from subsequent analysis. As to affective judgment, three subjects judged all the slides as "Neutral" and one subject judged all as "Negative" under subliminal conditions, and two subjects judged all as Neutral under supraliminal conditions. Because of small subject size and the relatively large number of these inappropriate responses, we did not include the data of subjective affective judgement in the following analysis. The mean SSR magnitudes were calculated for each of the six subjects in eight conditions (arm $\times$ hemisphere $\times$ emotional content), rejecting any data larger than mean $+2 \mathrm{SD}$ as artifacts. Subsequently, $93 \%$ of the total data were used, and all the data were log-transformed.

\section{Statistical analysis}

Under both subliminal and supraliminal conditions, the SSR data were analyzed using a $2 \times 2 \times 2$ repeated-measures ANOVA performed on the mean magnitude in each subject with arm (lesion side/intact side), hemisphere (lesion side/intact side), and emotional content (negative/ neutral) as within-subject factors. Results were considered as significant whether the $p$ value was $<0.05$. 


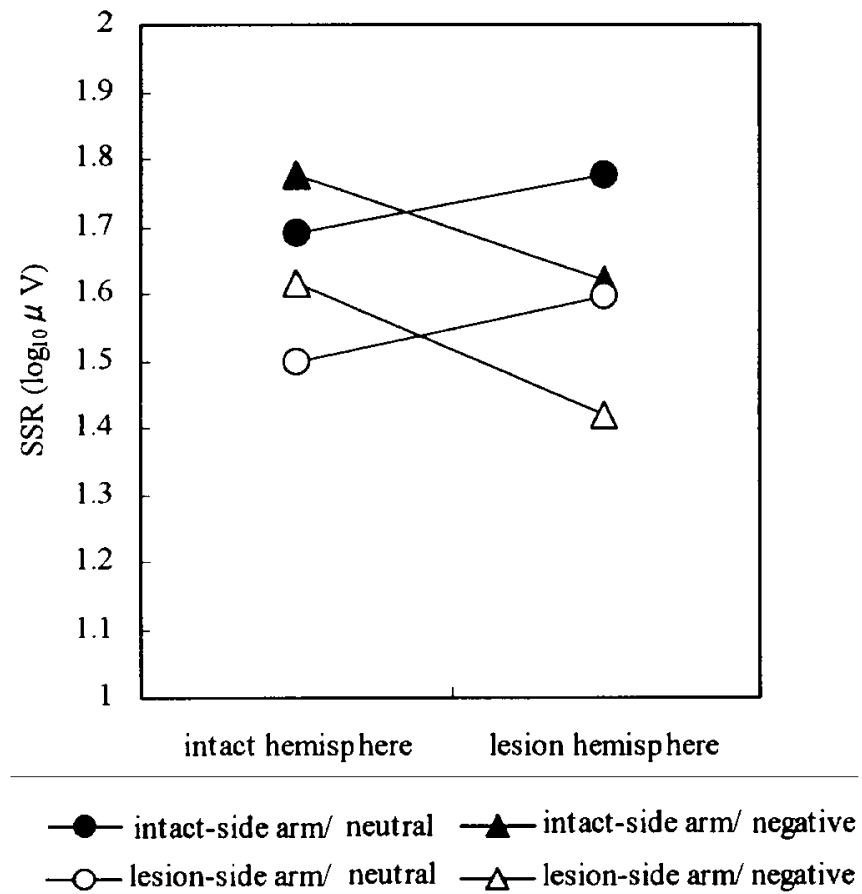

Figure 2. SSR magnitude under subliminal conditions. Mean of SSR magnitudes $\left(\log _{10} \mu \mathrm{V}\right)$ in six subjects in the case of intact hemisphere stimulation (left side) or in the case of lesion hemisphere stimulation (right side), recorded from intact-side arm (black marker) or lesion-side arm (white marker), in response to negative stimuli (circle marker) or neutral stimuli (triangle marker).

\section{RESULTS}

\section{SSR magnitude}

Under subliminal conditions, the main effect was found with the factor of arm. The magnitude of SSR from the intact-side arm was significantly greater than that from the lesion-side $\operatorname{arm}\left(F_{(1,5)}=\right.$ 13.7; $p=0.014$ ) (Fig. 2). A significant interaction was found between stimulated hemisphere and emotional content $\left(F_{(1,5)}=\right.$ 8.07; $p=0.036)$, indicating that in the case of stimulation of the intact hemisphere (i.e., the presentation of stimuli to the visual field contralateral to the operated side), the SSR response to negative stimuli was greater than that to neutral stimuli. Under supraliminal conditions, there were no significant differences (Fig. 3).

\section{DISCUSSION}

\section{Amygdala and subliminal emotional processing}

During intact hemisphere stimulation, higher EDAs were observed in response to negative slides than to neutral slides under the subliminal condition. In the case of the lesion hemisphere stimulation, no significant difference of EDA was observed between stimuli with different affective valence. On the other hand, no such discrepancy between the intact and lesion hemisphere stimulation was found under the supraliminal condition. These findings suggest that nonconscious emotional processing is reflected in EDA in a different manner from conscious emotional processing. The medial temporal structures, including the amygdala, thus appeared to play an important role in the neural substrates for such automatic emotional processing. To our knowledge, the present study is the first study in humans showing that unilateral medial temporal lesions have crucial effects on nonconscious emotional processing. These data are consistent with the proposal of LeDoux (1996) that the amygdala responds to early, crude representations of external stimuli. A recent neu-
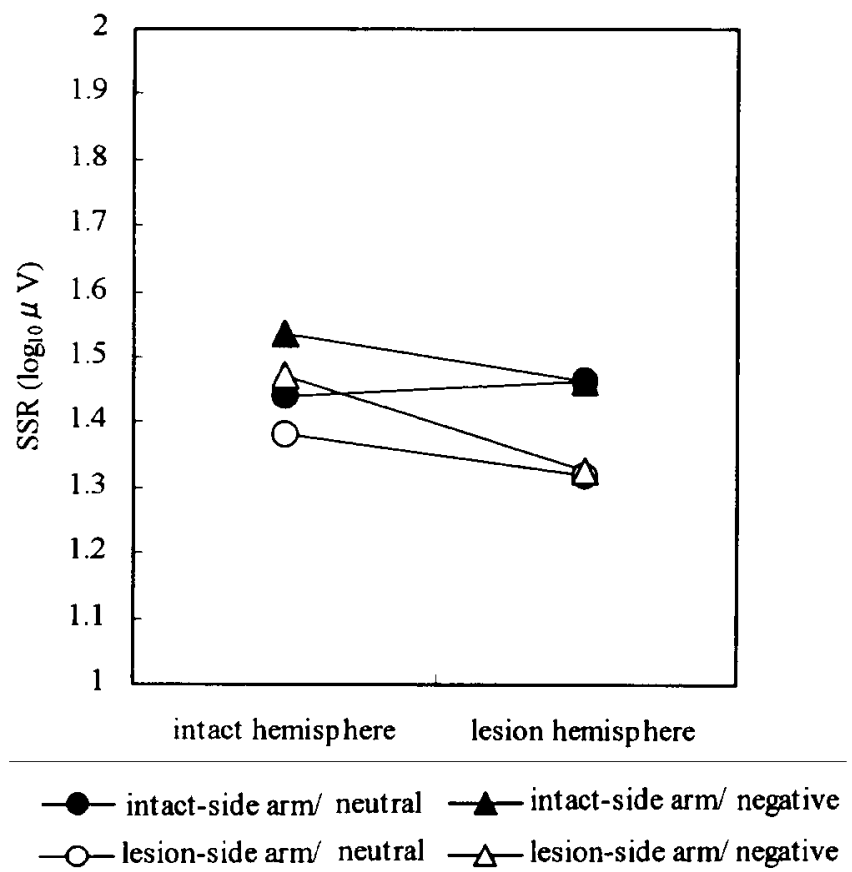

Figure 3. SSR magnitude under supraliminal conditions. Mean of SSR magnitudes $\left(\log _{10} \mu \mathrm{V}\right)$ in six subjects in the case of intact hemisphere stimulation (left side) or in the case of lesion hemisphere stimulation (right side), recorded from intact-side arm (black marker) or lesion-side arm (white marker), in response to negative stimuli (circle marker) or neutral stimuli (triangle marker).

roimaging study suggested that a subcortical pathway to the amygdala via the midbrain and thalamus provides a route for processing masked (unseen) emotional stimuli (Morris et al., 1999). Our results are also consistent with the hypothesis that the amygdala might receive stimuli information directly from the thalamus (LeDoux et al., 1985), although the present study does not address this issue directly. However, it should be noted that the extent of lesion in our subjects was not restricted to the amygdala. There is a possibility that the present findings might be attributable not only to amygdala lesion but also to extraamygdala damage.

Backward masking of emotional visual stimuli resulted in a characteristic pattern of EDA responses reflecting the unilateral medial temporal lesion. This is consistent with the functional imaging study in normal subjects by Whalen et al. (1998) that demonstrated the isolation of the amygdala activation in response to masked fearful face versus masked happy face targets. Under the condition without masking, no significant differences of EDA were observed. This might be because emotional processing with awareness is a highly complex cognitive process, involving not only the amygdala but also other neocortical neural connections. Whereas a role for the amygdala in emotion is crucial, it can be compensated for by other structures in the case of supraliminal processing even with an amygdala lesion. This does not exclude the possibility that the amygdala is involved in supraliminal processing, but the lesion effect might become relatively small in the above case. Our view is that the function of the amygdala in human emotional cognition would be much more specifically reflected in EDA in the case of subliminal processing.

\section{Two different modes of emotional cognition}

The present demonstration of automaticity in emotional processing casts light on the question of the amygdala function in highly complex emotional behavior in humans, the elucidation of which has been hampered by the rarity of cases with selective bilateral amygdala lesions. Notably, the literature does not provide satis- 
fying data on the relationships between ANS activity and amygdala functioning (for review, see Aggleton, 1992). Recent case studies in which electrophysiological measurement was performed are not unanimous as to the EDA responses to visual emotional stimuli. A decrease of EDA after bilateral amygdalectomy was reported by Lee et al. (1988). In contrast, normal EDA in response to emotional visual stimuli has been reported in patients with bilateral amygdala damage due either to UrbachWiethe disease (Tranel and Hyman, 1990) or to encephalitis (Tranel and Damasio, 1989). Studies in subjects after temporal lobectomy that were specifically designed to assess hemispheric asymmetries noted that EDA responses while subjects were viewing emotional stimuli were unrevealing (Davidson et al., 1992). These studies did not use a subliminal cognition paradigm. Thus, the results might have been obscured by EDA responses reflecting activation of various brain structures other than the amygdala.

Our subjects showed a considerable number of unusual responses on the affective rating of the stimuli both under subliminal and under supraliminal conditions. The rating under subliminal conditions were considered to be unreliable because the subjects could not identify the stimuli. Nevertheless, our subjects, under subliminal conditions, showed EDA responses that were congruent with the emotional valence of the stimuli. On the other hand, typical EDA responses to the emotional stimuli were not obtained under supraliminal conditions, which may suggest a influence of the affective judgement on EDA under these conditions. Therefore, there is a possibility that EDA under supraliminal conditions may be confounded with cortical influences associated with conscious processing of the stimuli. This is in accordance with our view above mentioned and might account for the failure to find impaired EDA in patients with amygdala lesions in previous studies.

From our present findings, we postulate that there exist two different, probably hybrid systems of emotional cognition in humans: (1) Preconscious processing: performed in the medial temporal circuitry of the unilateral side; the amygdala probably plays a key role in it. This process is closely related to body ANS activities and may parallel or be situated on the way to emotional processing with awareness. (2) Conscious processing: further complex information processing which involves sensory cortices and higher-order association cortices. The latter process might be related to other higher brain functions such as memory of personal experiences or social value judgements.

\section{Interarm differences}

Higher EDAs from the arm ipsilateral to the intact amygdala were observed only under subliminal conditions. The tendency was observed regardless of the affective valence of the stimulus, suggesting that the amygdala also plays an important role in the control of the unilateral output of EDA. A recent study of intracerebral stimulation showed that limbic structures, including the amygdala, were related to ipsilateral electrodermal control (Mangina and Beuzeron-Mangina, 1996). This is in line with our finding that a unilateral amygdala lesion has an effect on the ipsilateral output of EDA. Boucsein (1992) proposed that there are two neural pathways mediating EDA: (1) Ipsilateral hypothalamic influences on EDA with facilitary influences stemming from the amygdala, and (2) Contralateral influences from the basal ganglia together with premotor cortical areas. This hypothesis leads to the inference that the ipsilateral pathway is probably mainly related to emotional processing without awareness. Our finding that the effect of the amygdala lesion was observed only under subliminal conditions was in accord with the abovedescribed hypothesis. A recent functional magnetic resonance imaging (fMRI) study investigated the cortical basis of the EDA, and it was reported that areas implicated in emotion, particularly ventromedial prefrontal regions, are differently involved in generation and representation of EDA (Critchley et al., 2000). Fur- ther studies are needed to investigate the role of the amygdala in EDA control in humans, and we believe that the subliminal cognition paradigm applied in the present study is potentially important for providing directions for future research.

\section{REFERENCES}

Adolph R, Tranel D, Damasio H, Damasio D (1994) Impaired recognition of emotion in facial expressions following bilateral damage to the human amygdala. Nature 372:669-672.

Adolph R, Tranel D, Damasio H, Damasio D (1995) Fear and the human amygdala. J Neurosci 15:5879-5891.

Adolph R, Tranel D, Hamann AW, Young AW, Calder AJ, Phelps EA, Anderson A, Lee GP, Damasio AR (1999) Recognition of facial emotion in nine individuals with bilateral amygdala damage. Neuropsychologia 37:1111-1117.

Aggleton JP (1992) The amygdala: neurobiological aspects of emotion, memory, and mental dysfunction. New York: Wiley.

Bauer RS (1984) Autonomic recognition of names and faces in prosopagnosia: a neuropsychological application of the Guilty Knowledge Test. Neuropsychologia 22:457-469.

Bechara A, Tranel D, Damasio H, Adolphs R, Rockland C, Damasio AR (1995) Double dissociation of conditioning and declarative knowledge relative to the amygdala and hippocampus in humans. Science 269:1115-1118.

Bechara A, Damasio H, Damasio AR, Lee GP (1999) Different contributions of the human amygdala and ventromedial prefrontal cortex to decision-making. J Neurosci 19:5473-5481.

Boucsein W (1992) Electrodermal activity. New York: Plenum.

Breiter HC, Etcoff NL, Whalen PJ, Kennedy WA, Rauch SL, Buckner RL, Strauss MM, Hyman SE, Rosen BR (1996) Response and habituation of the human amygdala during visual processing of facial expression. Neuron 17:875-887.

Broks P, Young AW, Maratos EJ, Coffey PJ, Calder AJ, Isaac CL, Mayes AR, Hodges JR, Montaldi D, Cezayirli E, Roberts N, Hadley D (1998) Face processing impairments after encephalitis: amygdala damage and recognition of fear. Neuropsychologia 36:59-70.

Brothers L, Ring B, Kling A (1990) Response of neurons in the macaque amygdala to complex social stimuli. Behav Brain Res 41:199-213.

Calder AJ, Young AW, Rowland D, Perrett DI, Hodges JR, Etcoff NL (1996) Facial emotion recognition after bilateral amygdala damage: differentially severe impairment of fear. Cognit Neuropsychol 13:699-745.

Claus D, Schondorf R (1999) Sympathetic skin response. In: Recommendation for the practice of clinical neurophysiology: guidelines of the international federation of clinical physiology (Deuschl G, Eisen A, eds). Electroencephalogr Clin Neurophysiol [Suppl] 52:277-282.

Critchley HD, Elliott R, Mathias CJ, Dolan RJ (2000) Neural activity relating to generation and representation of galvanic skin conductance responses: a functional magnetic resonance imaging study. J Neurosci 20:3033-3040.

Davidson RA, Fedio P, Smith BD, Aureille E, Martin A (1992) Lateralized mediation of arousal and habituation: differential bilateral electrodermal activity in unilateral temporal lobectomy patients. Neuropsychologia 30:1053-1063.

Esteves F, Öhman A (1993) Masking the face: recognition of emotional facial expressions as a function of the parameters of backward masking. Scand J Psychol 34:1-18.

Furmark T, Fisher H, Wik G, Larsson M, Fredrikson M (1997) The amygdala and individual differences in human fear conditioning. NeuroReport 8:3957-3960.

Gaffan D, Gaffan EA, Harrison S (1989) Visual-visual associative learning and reward-association learning in monkeys: the role of the amygdala. J Neurosci 9:558-564.

Geschwind N (1965) Disconnection syndromes in animals and man. Brain 88:237-294.

Goldstein LE, Rasmusson AM, Bunney BS, Roth RH (1996) Role of the amygdala in the coordination of behavioral, neuroendocrine, and prefrontal cortical monoamine responses to psychological stress in the rat. J Neurosci 16:4787-4798.

Hamann SB, Adolph R (1999) Normal recognition of emotional similarity between facial expressions following bilateral amygdala damage. Neuropsychologia 37:1135-1141.

LaBar KS, LeDoux JE, Spencer DD, Phelps EA (1995) Impaired fear conditioning following unilateral temporal lobectomy in humans. J Neurosci 15:6846-6855.

Lang PJ, Bradley MM, Cuthbert BN (1995) The international affective picture system (IAPS): photographic slides. The Center for Research in Psychophysiology, University of Florida.

LeDoux JE (1996) The emotional brain. New York: Simon and Shuster.

LeDoux JE, Ruggiero DA, Reis DJ (1985) Projection to the subcortical forebrain from anatomically defined regions of the medial geniculate body in the rat. J Comp Neurol 242:182-213.

LeDoux JE, Farb C, Ruggiero DA (1990) Topographic organization of 
neurons in the acoustic thalamus that project to the amygdala. J Neurosci 10:1043-1054.

Lee GP, Arena JG, Meador KJ, Smith JR, Loring DW, Flanigin HF (1988) Changes in autonomic responsiveness following bilateral amygdalotomy in humans. Neuropsychiatry Neuropsychol Behav Neurol $1: 119-129$.

Mangina CA, Beuzeron-Mangina JH (1996) Direct electrical stimulation of specific human brain structures and bilateral electrodermal activity. Int J Psychophysiol 22:1-8.

Morris JS, Frith CD, Perrett DI, Rowland D, Young AW, Calder AJ, Dolan RJ (1996) A differential neural response in the human amygdala to fearful and happy facial expressions. Nature 383:812-815.

Morris JS, Öhman A, Dolan RJ (1998) Conscious and unconscious emotional learning in the human amygdala. Nature 393:467-470.

Morris JS, Öhman A, Dolan RJ (1999) A subcortical pathway to the right amygdala mediating "unseen" fear. Proc Natl Acad Sci USA 96:1680-1685.

Nakamura K, Mikami A, Kubota K (1992) Activity of single neurons in the monkey amygdala during performance of a visual discrimination task. J Neurophysiol 67:1447-1463.

Nishijo H, Ono T, Nishino H (1988) Single neuron responses in amyg- dala of alert monkey during complex sensory stimulation with affective significance. J Neurosci 8:3570-3583.

Tranel D, Damasio H (1988) Nonconscious face recognition in patients with face agnosia. Behav Brain Res 30:235-249.

Tranel D, Damasio H (1989) Intact electrodermal skin conductance responses after bilateral amygdala damage. Neuropsychologia 27:381-390.

Tranel D, Hyman BT (1990) Neuropsychological correlates of bilateral amygdala damage. Arch Neurol 47:349-55.

Whalen PJ, Rauch SL, Etcoff NL, McInerney SC, Lee MB, Jenike MA (1998) Masked presentations of emotional facial expressions modulate amygdala activity without explicit knowledge. J Neurosci 18:411-418.

Weiskrantz L (1956) Behavioral changes associated with ablation of the amygdaloid complex in monkeys. J Comp Physiol Psychol 49:381-391.

Yokota T, Matsunaga T, Okiyama R, Hirose K, Tanabe H, Furukawa T, Tsukagoshi H (1991) Sympathetic skin response in patients with multiple sclerosis compared with patients with spinal cord transection and normal controls. Brain 114:1381-1394.

Young AW, Aggleton JP, Hellawell DJ, Johnson M, Broks P, Hauley JR (1995) Face processing impairments after amygdalotomy. Brain 118: $15-24$. 